Portland State University

PDXScholar

$5-27-2017$

\title{
A Probe for Characterization of Natural Phenomena Using the Modulated Scattering Technique
}

Daniel D. Schaeffer

Portland State University

Follow this and additional works at: https://pdxscholar.library.pdx.edu/honorstheses

Let us know how access to this document benefits you.

\section{Recommended Citation}

Schaeffer, Daniel D., "A Probe for Characterization of Natural Phenomena Using the Modulated Scattering Technique" (2017). University Honors Theses. Paper 390.

https://doi.org/10.15760/honors.385

This Thesis is brought to you for free and open access. It has been accepted for inclusion in University Honors Theses by an authorized administrator of PDXScholar. Please contact us if we can make this document more accessible: pdxscholar@pdx.edu. 
A Probe for Characterization of Natural Phenomena Using the Modulated Scattering Technique

by

\section{Daniel Schaeffer}

An undergraduate honors thesis submitted in partial fulfillment of the requirements for the degree of

Bachelor of Science

in

University Honors

and

Electrical Engineering

Thesis Adviser

Dr. Richard Campbell

Portland State University 


\title{
A Probe for Characterization of Natural Phenomena Using the Modulated Scattering Technique
}

\author{
Daniel Schaeffer \\ Maseeh College of Engineering \\ Portland State Univercity \\ Portland OR, United States of America \\ dds2@pdx.edu
}

\begin{abstract}
This project aims to provide students and researchers with low cost, low power, lightweight probes for characterizing natural phenomena. To achieve this, the probes are designed using the modulated scattering technique, which in this application provides a system somewhat analogous to a hybrid radar and RFID system. The achieved design is one square inch in area, less than $\mathbf{1 0}$ grams, and easily has a battery life of over 20 days using two CR2032 batteries in series.
\end{abstract}

\section{INTRODUCTION}

The purpose of this project is to design, build, and test low cost, low power, lightweight probes that utilize the modulated scattering technique to characterize natural phenomena.

Though methods exist already for the purposes of tracking oil spills and other environmental phenomena, they often utilize GPS, satellites, or sensor networks that can be quite expensive or complicated in application [1][2][3]. This project aims to provide researchers and students an option for low cost instrumentation that can be used to measure environmental phenomena. To achieve a low cost, an alternative probing method is proposed which uses the modulated scattering technique to create relatively simple probes.

\section{THEORY}

The modulated scattering technique is a technique often reserved for near field measurements. Measurement of near field electric field intensities is often difficult due to field distortion when a reflecting probe antenna is introduced. If an appropriately sized antenna is placed within the near field of an object to act as a reflector, it can alter the electric field making for inaccurate field mapping. So, a smaller antenna with less effect on field dynamics is used. With this comes the disadvantage of a weaker signal, but this is overcome by using an oscillator and a nonlinear device (such as a diode) to introduce modulation to the reflected signal. This allows the weaker signal from the probe to be distinguished from the stronger signal emanated by the object under test [4].

In the application used in this paper, the modulated scattering technique is applied to create a combined radar RFID system. The system has a receiver/transmitter that sends out a radar-like signal with specified frequency, which is then received by the probes and retransmitted with added modulation. Just like in the near field case, this retransmitted signal may be weaker than much of the environmental noise, but with the modulated signature the receiver/transmitter can separate out the probe's signal. Once the probe's signal is detected, standard radar methods can be used to find the distance and location of the probe. Specific modulation frequencies can be used for each probe to allow for accurate tracking of each probe separately, much like an RFID system. In the simplest of systems, probe modulation would be in the audio range, and the receiver in the system would simply have its output connected to a speaker. The speaker would act as a low pass, only letting the probe modulation frequency through. In this way, the transmitter/receiver could simply be pointed around until the strongest signal was heard through the speaker, and (with calibration) the amplitude and direction of strongest amplitude of the heard signal could be used to locate the probe.

\section{DESIGN}

A schematic from Dr. Richard Campbell's Instrumentation and Sensing class at Portland State University was used as a starting point for my design [5], as seen in Figure 1 below.

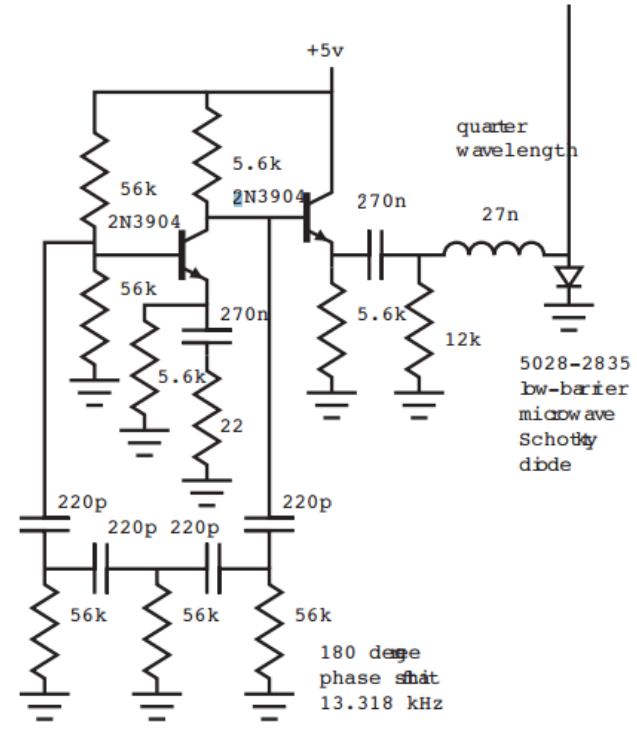

Figure 1: Original circuit schematic from Dr. Campbell's 2016 Instrumentation and Sensing class. 
Though the circuit in Figure 1 is fully functional, some alterations were made to better fit the application at hand. The circuit designed for this paper is seen in Figure 2.

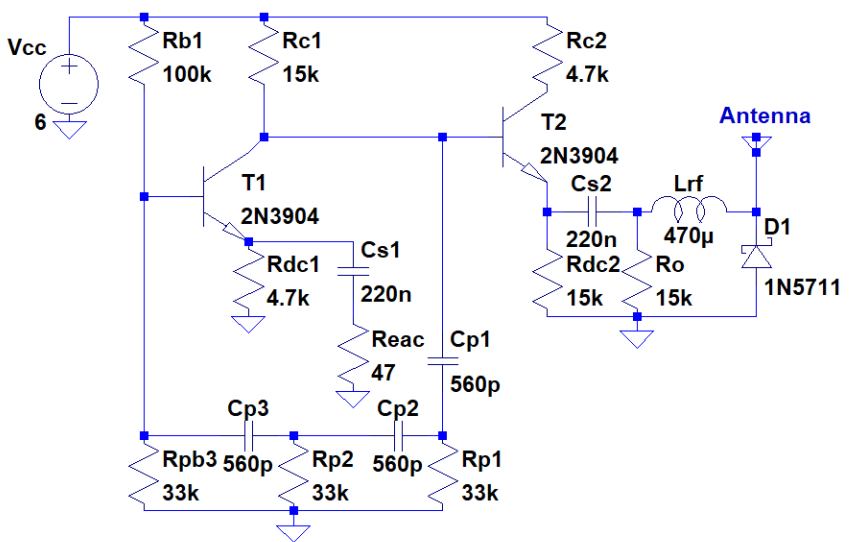

Figure 2: Final modulated scattering probe schematic.

From left to right, the circuit consists of a phase shift oscillator (T1), into a current amplifier (T2) that drives the mixer diode on the far right (D1). The phase shift network (Rp1-Rp3 and Cp1-Cp3) was chosen due to its easy application at lower frequencies compared to other oscillator topologies [7]. Cs2 blocks DC voltage from reaching D1. Lrf provides a high impedance choke to the incoming RF signal from the antenna. This decreases the amount of RF dissipation in the circuit, and increases signal reflection. D1 is a low barrier Schottky diode to achieve good high frequency switching performance. Also, the low barrier demands less voltage amplitude from the oscillator.

Changes from the circuit in Figure 1 to the final circuit in Figure 2 consist first of a lowered oscillator frequency, from $13.318 \mathrm{kHz}$ to $4 \mathrm{kHz}$, to accommodate for human hearing loudness curves, thereby making the modulation frequency more discernable by ear [6]. Oscillation frequency can be changed by altering the values of the capacitors in the phase shift network. The phase shift section was reduced to a three stage RC network to minimize part count. T1 and T2 were rebiased and surrounding components tuned to allow the circuit to draw half as much current. The diode was changed to a 1N5711 Schottky diode due to availability, and various other components were also changed for the same reason.

Another alteration that was considered was adding a lownoise amplifier (LNA) after the diode mixer to increase signal strength. This would likely require moving from a monostatic antenna configuration to a bistatic configuration (with the probe receiving antenna being separate from probe transmitting antenna). The bad seemed to outweigh the good for these alterations, though. The LNA would likely introduce frequency selectivity into the RF portion of the circuit, the bistatic configuration would introduce the possibility of crosstalk between probe antennas, and both alterations would increase the size and cost of the probes. One of the benefits of the circuit as designed is that it is mostly agnostic to carrier frequency; only the antenna length needs to be changed in order to adapt the circuit to a new system. The current design is well suited for either a monopole or dipole antenna, both of which can be easily manufactured and altered.

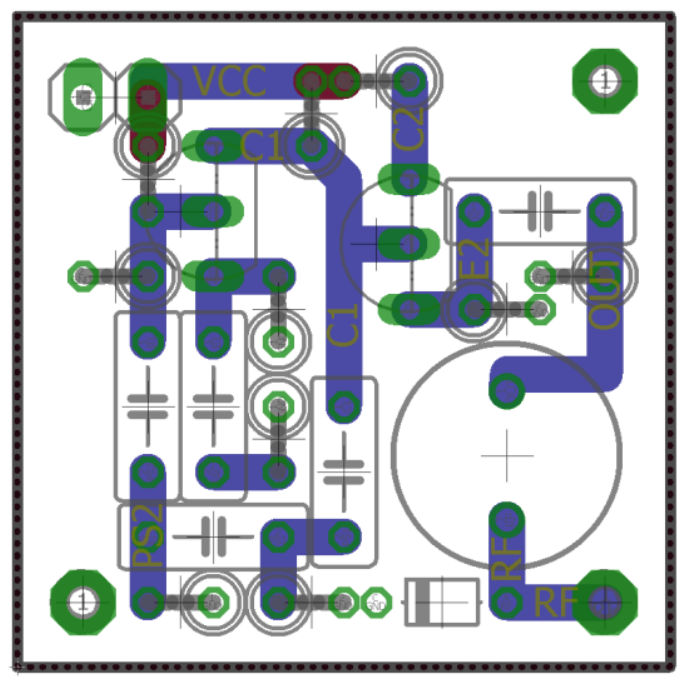

Figure 3: Modulated scattering probe circuit layout

The layout pictured in Figure 3 is the third revision of the board. It started out quite a bit larger at $1.6 \mathrm{in}^{2}$, but with some reconfiguring the final layout is $1 \mathrm{in}^{2}$. It is laid out analogously to the schematic, with Vcc input being handled by pinheaders for easy attachment of whatever battery is selected for powering the circuit. The antenna slot is in the lower right corner, with two auxiliary holes on adjacent corners that could be used for additional antennae, parasitics, or as mounting holes. Mechanical design beyond board design was not considered; the circuit's small size and light weight allow the board to be easily attachable to whatever chassis needed. SMD components were considered, but the relatively low frequencies handled in most of the circuit did not warrant their use, and they would be more difficult to assemble for the possible end user.

\section{RESUlTS AND APPLICATION NOTES}

As can be seen in the Figure 4, the fully assembled modulated scattering probe circuit is quite small, at 1 in. by 1 in. by 0.5 in. (length, width, height). The circuit itself, without a battery, weighs 7.1 grams $(0.25 \mathrm{oz}$.), light enough that a decent sized helium filled latex party balloon could likely lift the circuit. Balloons may be fitting if the probe is being applied to simple weather tracking. In aquatic applications, such as oil spill tracking, the circuit could be encased in candle wax for waterproofing, or easily be fit into most any enclosure. The main concern with any enclosure or deployment method is the orientation of the antenna. For the monopole or dipole antenna, the antenna should be oriented vertically so as to give receiving and reflecting maxima on the horizontal. 

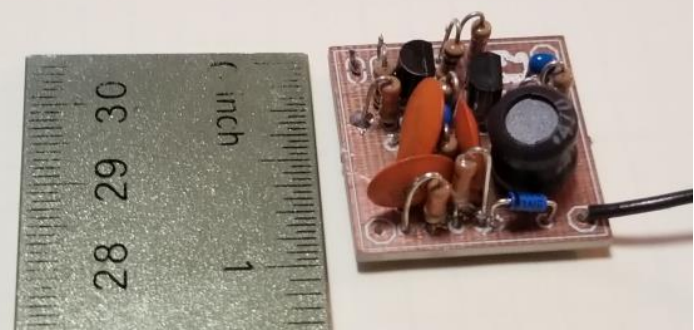

Figure 4: Modulated scattering probe fully assembled circuit

The size and low component count of the board make this design quite affordable. The components alone cost $\$ 2.70$ per board $^{1}$. If a PCB router is not available to do manufacturing, as was done for the board in Figure 4, the boards cost less than $\$ 2$ each $^{2}$. So, each individual board can be produced for less than $\$ 5$, and potentially far less if produced in bulk.

The circuit provides an approximately $13 \mathrm{kiloohm}$ load, giving a current draw of 421 microamps at 6 volts. This means that two CR2032 batteries in series could easily power the circuit for over 20 days.

The circuit was tested for functionality with various power supply voltages. It performed well from 4 volts up to 30 volts (the highest the power supply would go, and much higher than most any battery that would realistically be used for this circuit). Frequency varied with supply voltage, as seen in Figure 5 below.

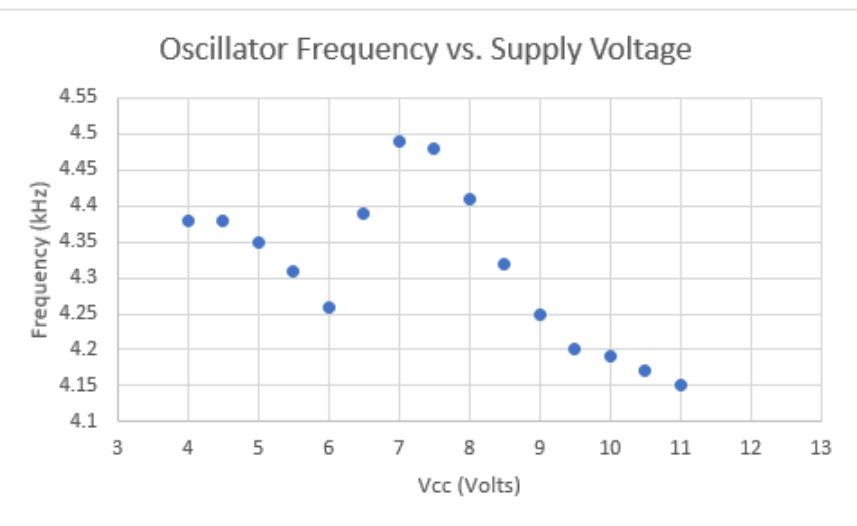

Figure 5: Oscillator frequency (taken at emitter of T1) vs. supply voltage.

If a 6 volt supply consisting of two CR2032 batteries were used, frequency variance would likely be less than $0.15 \mathrm{kHz}$. A 9 volt battery would provide a wider swing of about 0.4 $\mathrm{kHz}$. For this reason, if an array of these probes were to be used, with each probe having a unique oscillator frequency, it is recommended that frequencies be spaced at least $0.2 \mathrm{kHz}$ apart for probes using a 6 volt supply, and at least $0.5 \mathrm{kHz}$ for probes using a 9 volt supply. Future revisions of this circuit may have voltage regulation to combat this issue.

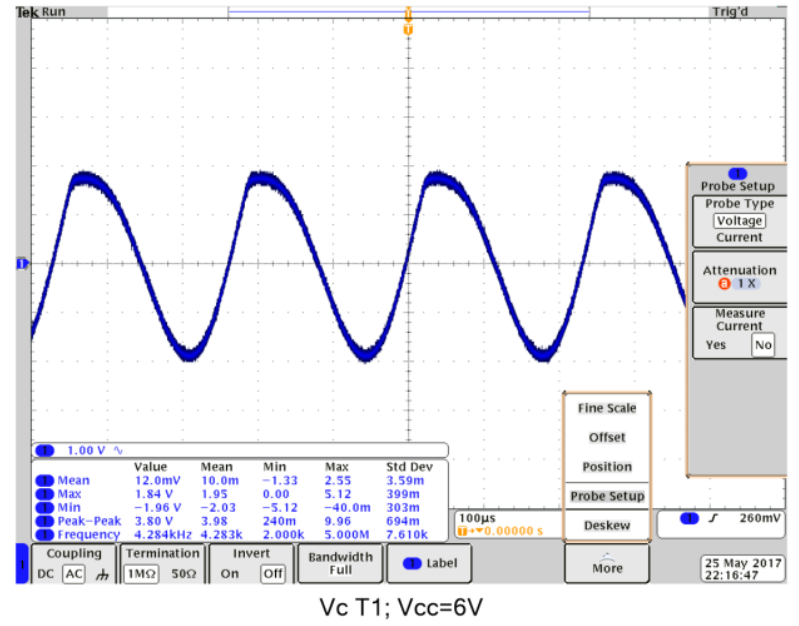

Figure 6: Voltage waveform at emitter of T1.

Figure 6 shows the oscillator output at the emitter of T1. The shape of this waveform is actually not critical to the operation of this circuit. As long as the signal has enough amplitude to turn the diode on and off at the desired modulation frequency, the circuit will function.

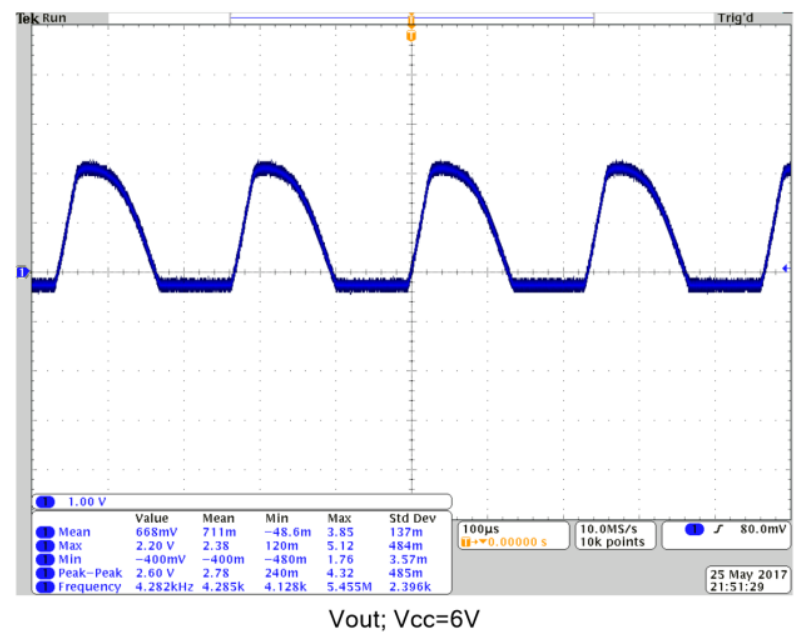

Figure 7: Voltage waveform at antenna using 6 volt power supply.

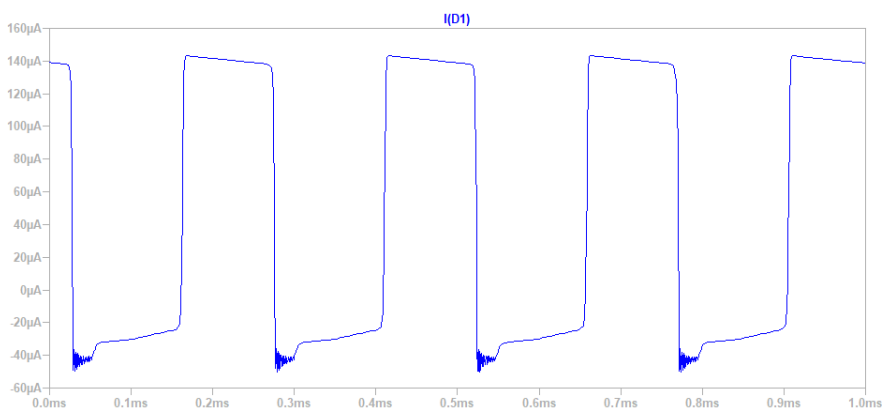

Figure 8: Circuit simulation diode (D1) current. 
Figure 7 shows the voltage at the antenna, across the diode. The flat portions at $-400 \mathrm{mV}$ are where the diode is conducting to ground, providing a low impedance path to ground for the RF signal (see Figure 8). Hence, the diode is effectively modulating the incoming RF signal by a square wave (alternating between multiplying the RF signal by 1 and 0 ad infinitum at the oscillator frequency), with a duty cycle of $61 \%$. Lower voltage power supplies will increase the duty cycle, since less of the wave will be under the $-400 \mathrm{mV}$ threshold; the inverse is also true for higher voltage supplies.

The circuit was tested with a $70-\mathrm{cm}$ band transmitter/receiver system in the Portland State University Integrated Circuits Design and Test Laboratory, and the circuit was successfully able to reflect a modulated signal back to the receiver. This testing used a simple quarter-wave monopole antenna. The major area for improving performance of the reflector will be in utilizing more efficient antenna designs, such as the dipole antenna. Directional antenna designs, such as the Yagi-Uda, would not be fitting for this circuit, as the antenna's radiation pattern must be able to cover the whole horizontal plane. An antenna array could be spread across the board, but special consideration would have to be made for frequency specific phase delay. This would make adapting the board to different frequency systems more difficult, as board size and layout would likely need to be adjusted to the space needs of different frequencies.

\section{CONCLUSION}

The circuit provided in this paper provides a low cost, low power, lightweight probe that is accessible and easily usable for students and researchers. Though the circuit has been tested and works, further testing is planned. More comprehensive field testing in possible real world applications will allow for a more detailed evaluation of the circuit's performance in terms of reflection efficiency, actual battery life, and circuit resiliency and applicability.

\section{REFERENCES}

[1] A. B. Ages, B. R. de Lange Boom, and M. J. Woodward, "A drifter for tracking oil spills using the Argos system," in Proceedings of OCEANS'94, vol. 3, p. III/292-III/297.

[2] R. Tiwari, M. T. Thai, and A. Helal, "Localized Energy Efficient Detection and Tracking of Dynamic Phenomena," in 2010 IEEE Global Telecommunications Conference GLOBECOM 2010, 2010, pp. 1-5.

[3] N. Sharma, P. Brickley, G. Owen, and P. Coholan, "Use of air-deployed drogued drifting buoys for oil spill tracking," in OCEANS 2010 MTS/IEEE SEATTLE, 2010, pp. 1-9.

[4] J. C. Bolomey and F. E. Gardiol, Engineering Applications of the Modulated Scatter Technique. Boston: Artech House Publishers, 2001.

[5] R. L. Campbell, "ECE 510 Instrumentation and Sensing Study Guide \#7," 2016, http://web.cecs.pdx.edu/ campbell/IS2016StudyGuide7.pdf [Accessed 5 May, 2017]

[6] B. Bauer and E. Torick, "Researches in loudness measurement," in IEEE Transactions on Audio and Electroacoustics, vol. 14, no. 3, pp. 141-151, Sep 1966.

[7] P. Horowitz and W. Hill, The Art of Electronics, 3rd ed. Cambridge: Cambridge University Press, 2015. 